\title{
Pengelolaan Ekosistem Lamun untuk Keberlanjutan Populasi Kuda Laut di Desa Sebong Pereh, Kabupaten Bintan
}

\section{(Management of the Seagrass Ecosystem for Sustainability of Sea Horse Population on Sebong Pereh Village, Bintan District)}

\author{
Rizqan Khairan Munandar ${ }^{1 *}$, Sulistiono ${ }^{2}$, Isdrajad Setyobudiandi ${ }^{2}$
}

(Diterima April 2019/Disetujui Mei 2020)

\begin{abstract}
ABSTRAK
Penelitian ini bertujuan untuk mengetahui kondisi ekosistem lamun, menganalisis keterkaitan hubungan ekosistem lamun, lingkungan perairan, dan populasi kuda laut, menganalisis sebaran ekosistem lamun dan kelimpahan kuda laut, dan menganalisis strategi pengelolaan ekosistem lamun berbasis kuda laut. Penelitian ini dilakukan pada bulan Maret-Juni 2017. Penentuan stasiun penelitian dilakukan berdasarkan teknik purposive sampling. Pengambilan data ekosistem lamun dilakukan dengan menggunakan transek kuadran berukuran 50 x 50 $\mathrm{cm}$. Pengambilan data kuda laut dilakukan dengan menggunakan visual sensus di transek lamun dengan plot berukuran $100 \times 100 \mathrm{~cm}$. Hubungan antara parameter lingkungan, ekosistem lamun, dan kuda laut dihitung dengan menggunakan XL Start 2015. Pengelolaan ekosistem lamun dianalisis menggunakan SWOT. Analisis lamun meliputi jenis, kerapatan, dan Indeks Nilai Penting (INP), sementara analisis kuda laut menghitung kelimpahan. Penelitian ini menemukan 6 jenis lamun, yaitu Enhalus acoraides (Ea), Thalassia hemprichii (Th), Halophila ovalis (Ho), Syringodium isoetifolium (Si), Cymodocea serrulata (Cs), dan Thalassodendron ciliatum (Tc) dengan kerapatan yang meliputi kelimpahan kuda laut, dan INP yang memiliki peranan suatu jenis di lokasi penelitian. Pengelolaan dilakukan dengan tujuan untuk mempertahankan sumber daya yang berkelanjutan.
\end{abstract}

Kata kunci: Desa Sebong Pereh, ekosistem lamun, kuda laut

\section{ABSTRACT}

This research is about studying ecosystems that was designed to analyze the relationship between seagrass ecosystem, environmental competition, and seahorse participation to analyze the distribution of seagrass ecosystems and the abundance of sea horses, and to analyze seahorse-based ecosystem management strategies. This research was conducted in March-June 2017. The determination of the research station was based on purposive sampling technique. Retrieval of seagrass ecosystem data was conducted using a quadrant with the size of $50 \times 50$ $\mathrm{cm}$ transect. Seahorse data were collected using visual census on seagrass transect with a plot of $100 \times 100 \mathrm{~cm}$. The relationships between environmental parameters, seagrass ecosystems, and seahorses were calculated using XL Starting 2015. Management of seagrass ecosystems was analyzed using SWOT. Analysis of seagrass included type, density, and INP. Seahorse analysis calculated the abundance of seahorse. The results found 6 species of seagrasses, namely Enhalus acoraides (Ea), Thalassia hemprichii (Th), Halophila ovalis (Ho), Syringodium isoetifolium (Si), Cymodocea serrulata (Cs), and Thalassodendron ciliatum (Tc) with a density that covered sea horse abundance, and INP which had several types of roles in the research location. The management is carried out with the objectives of sustainable resources.

Keywords: seagrass ecosystem, seahorse, Sebong Pereh Village

\section{PENDAHULUAN}

Lamun (seagrass) adalah satu-satunya tumbuhan berbunga yang terdapat di lingkungan laut (Romimohtarto \& Juwana 2001). Lamun memiliki peranan penting dalam ekosistem sebagai tempat memijah, mencari makan, pembesaran, serta tempat

1 Sekolah Pascasarjana, Fakultas Perikanan dan IImu Kelautan, Institut Pertanian Bogor, Kampus IPB Darmaga, Bogor 16680

2 Departemen Manajemen Sumberdaya Perairan, Fakultas Perikanan dan IImu Kelautan, Institut Pertanian Bogor, Kampus IPB Darmaga, Bogor 16680

* Penulis Korespondensi: Email: rkmunandar@gmail.com berlindung bagi berbagai biota, seperti ikan, udang, dan moluska (Nybakken 1992).

Ekosistem lamun sudah banyak terancam, baik secara alami maupun oleh aktivitas manusia (Juraij 2016). Hewan yang memanfaatkan ekosistem lamun salah satunya ialah kuda laut (Hippocampus spp.). Biota ini termasuk dalam famili Syngnathidae, yang dikenal juga sebagai tangkur kuda. Di Indonesia, sejak tahun 1990 telah terjadi penurunan hasil tangkapan kuda laut sebesar 15-50\% (Perante et al. 1998). Indonesia memanfaatkan kuda laut sebagai bahan TCM (Traditional China Medicine), bahan jamu, souvenir, dan azimat, sementara kuda laut hidup biasanya dijual ke pedagang akuarium untuk diekspor (Vincent 1996). Dengan penurunan kuda laut di alam, 
CITES memasukkan semua spesies kuda laut ke dalam daftar Apendiks 2 pada conference of party ke12 tahun 2002, dan CITES merekomendasikan batas ukuran penjualan kuda laut adalah $10 \mathrm{~cm}$. Akan tetapi, nelayan di Desa Sebong Pereh masih menangkap kuda laut dengan berbagai ukuran karena harga jual kuda laut kering bisa mencapai Rp5-6 juta/kg (Sadili et al. 2015).

Kerusakan yang terjadi pada ekosistem lamun setiap tahunnya membuat biota yang memanfaatkan ekosistem lamun akan berkurang dan masyarakat yang memanfaatkan jasa ekosistem lamun mengalami penurunan hasil tangkapan sehingga dibutuhkan peran serta masyarakat. Program pengelolaan berbasis masyarakat adalah memberdayakan masyarakat agar dapat berperan serta secara aktif dan terlibat langsung dalam pengelolaan sumber daya alam lokal untuk menjamin dan menjaga kelestarian pemanfaatan sumber daya tersebut. Pendekatan pemberdayaan dilakukan secara organisasi atau berkelompok agar terlihat pemberdayaan masyarakat berjalan dengan baik (Utomo et al. 2018). Pengelolaan sumber daya berbasis masyarakat merupakan salah satu strategi pengelolaan yang dapat meningkatkan efisiensi dan keadilan dalam pemanfaatan dan pengelolaan sumber daya alam (Harahap \& Raymond 2011). Untuk pengeIolaan ekosistem lamun berbasis masyarakat di Pulau Bintan, Kecamatan Teluk Sebong, Desa Sebong Pereh sangat diperlukan karena pada saat musim kuda laut, nelayan melakukan penangkapan secara intensif yang membuat ekosistem lamun terganggu dan hasil tangkapan kuda laut setiap tahunnya menjadi berkurang.

Berdasarkan uraian di atas, tujuan penelitian ini adalah untuk mengetahui kondisi ekosistem lamun, menganalisis keterkaitan hubungan antara ekosistem lamun, lingkungan perairan, dan populasi kuda laut, menganalisis sebaran ekosistem lamun dan kelimpahan kuda laut, serta menganalisis strategi pengelolaan ekosistem lamun berbasis kuda laut.

\section{METODE PENELITIAN}

\section{Waktu dan Tempat}

Penelitian ini dilaksanakan selama Maret-Juni 2017 di Desa Sebong Pereh, Kecamatan Teluk Sebong, Kabupaten Bintan, Kepulauan Riau. Pengukuran parameter dalam penelitian ini dilakukan di 3 stasiun dan masing-masing stasiun memiliki 3 transek sebagai ulangan. Posisi stasiun penelitian dapat dilihat pada Gambar 1.

\section{Pengambilan Data Lapangan}

Pengukuran kualitas perairan dilakukan secara in situ. Pengukuran dilakukan dengan cara mengambil contoh air pada masing-masing stasiun pengamatan. Parameter kualitas perairan yang diukur meliputi salinitas, suhu, arus, kekeruhan, TSS (Total suspended solid), Potential Hydrogen $(\mathrm{pH})$, oksigen terlarut atau dissolved oxygen (DO), nitrat $\left(\mathrm{NO}_{3}\right)$, dan fosfat $\left(\mathrm{PO}_{4}-\mathrm{P}\right)$.

Stasiun penelitian ditentukan pada daerah penangkapan kuda laut di ekosistem lamun. Pada setiap stasiun terdapat 3 transek yang panjangnya dari darat ke laut sepanjang $100 \mathrm{~m}$, dan ke arah kiri dan kanan diberi jarak $50 \mathrm{~m}$, pada setiap garis transek diamati ekosistem lamun dengan bantuan transek plot berukuran $50 \times 50 \mathrm{~cm}$ yang dimulai dari titik $0 \mathrm{~m}$ dan diulangi setiap jarak $20 \mathrm{~m}$ (Rahmawati et al. 2014). Parameter yang dianalisis adalah jenis lamun, kerapatan lamun, dan indeks nilai penting.

Metode yang digunakan dalam survei kuda laut ialah visual census, yang berenang secara perlahan sepanjang transek sejauh $100 \mathrm{~m}$ (Calef et al. 2011). Perhitungan individu kuda laut dilakukan pada plot lamun dengan ukuran luas $100 \times 100 \mathrm{~cm}$, dengan bantuan transek plot berukuran $1 \times 1 \mathrm{~m}$ yang dimulai dari titik $0 \mathrm{~m}$ dan diulangi setiap jarak $20 \mathrm{~m}$ tanpa membedakan spesies

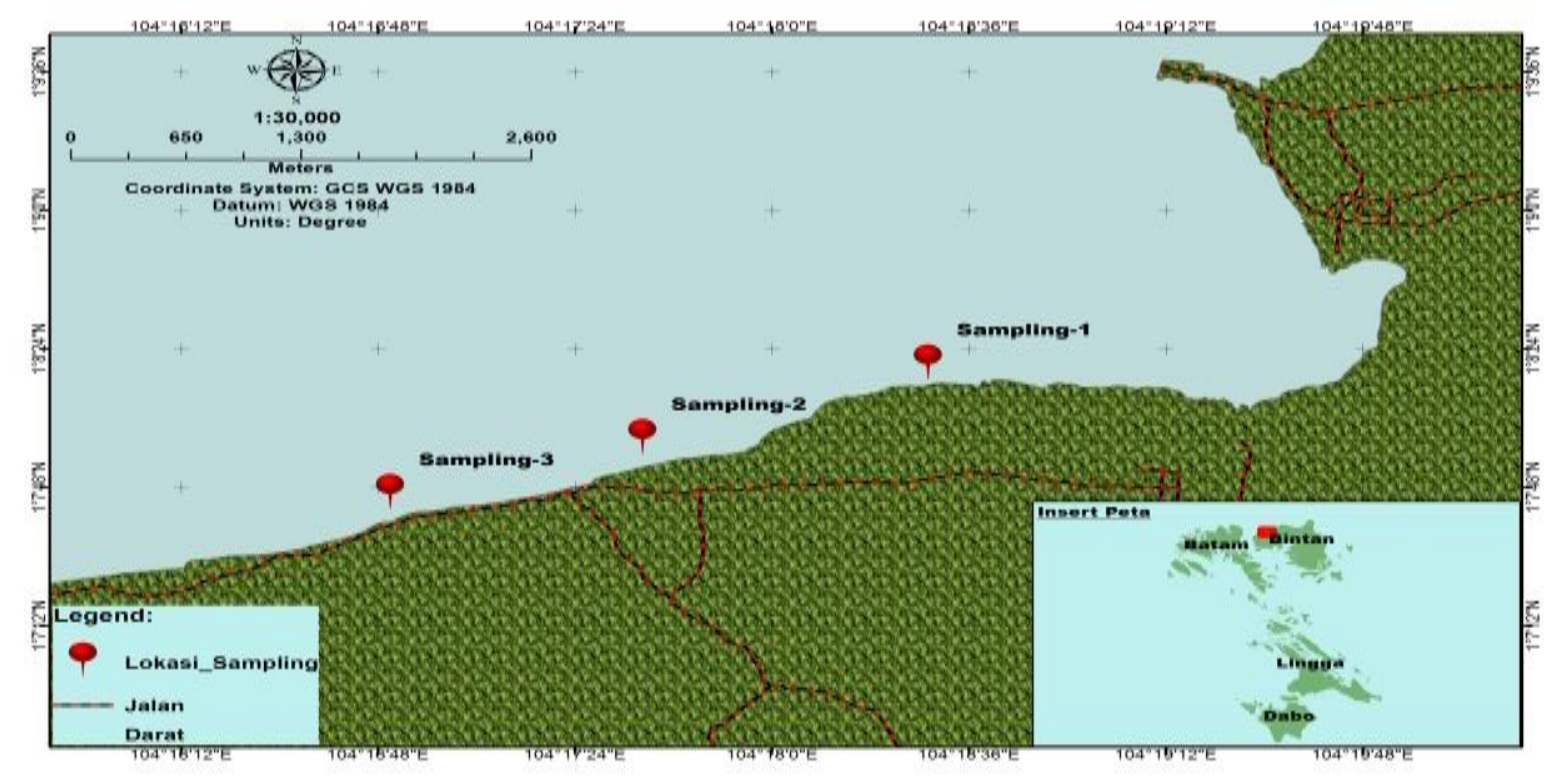

Gambar 1 lokasi penelitian di Desa Sebong Pereh. 
Data yang diperoleh (jenis lamun, kondisi lingkungan, dan populasi kuda laut) diolah dengan metode statistika, yaitu principal component analysis (PCA) dengan menggunakan XL-STAT 2018 (trial version) yang disajikan dalam bentuk tabel dan gambar. Kegiatan survei yang berkaitan dengan masyarakat dilakukan dengan menggunakan metode wawancara terstruktur melalui teknik pengumpulan data (Sugiyono 2015) dengan responden adalah nelayan kuda laut yang melakukan penangkapan di kawasan Sebong Pereh. Data yang diperoleh dari kuesioner dianalisis menggunakan analisis SWOT (Rangkuti 2011).

\section{HASIL DAN PEMBAHASAN}

\section{Parameter Lingkungan}

Parameter lingkungan yang diamati pada setiap stasiun mewakili kawasan penelitian (ekosistem lamun dan daerah penangkapan kuda laut) untuk mengetahui kawasan tersebut tercemar atau tidak. Berdasarkan perolehan nilai parameter lingkungan, disimpulkan bahwa kondisi lingkungan dikategori baik untuk kehidupan biota laut walaupun ada aktivitas penangkapan pada saat musim kuda laut. Kondisi lingkungan yang seperti ini juga mendukung kehidupan ekosistem lamun. Nilai parameter tersebut disajikan pada Tabel 1.

\section{Ekosistem Lamun di Lokasi Penelitian \\ - Jenis lamun}

Jenis-jenis lamun yang ditemukan dari hasil pengamatan pada tiga stasiun penelitian yakni, terdapat jenis lamun yang sangat beragam dari jenis yang kecil hingga yang besar jenis-jenis lamun tersebut ditampilkan pada Tabel 2.
Berdasarkan hasil penelitian ini, ditemukan enam jenis lamun yang terdapat di perairan Desa Sebong Pereh. Pada Stasiun 1 ditemukan enam jenis, yaitu Enhalus acoroides, Thalassia hemprichii, Halophila ovalis, Syringodium isoetifolium, Cymodocea serrulata, dan Thalassodendron ciliatum. Pada Stasiun 2 ditemukan empat jenis lamun, yaitu Enhalus acoroides, Thalassia hemprichii, Halophila ovalis, dan Thalassodendron ciliatum. Pada Stasiun 3 ditemukan dua jenis lamun, yaitu Enhalus acoroides dan Thalassia hemprichii. Hemminga \& Duarte (2000) menyatakan bahwa karakteristik padang lamun di daerah tropis dan subtropis Indo-Pasifik memiliki keanekaragaman jenis yang tinggi dan bertipe vegetasi campuran (mixed vegetation). Kondisi perairan Desa Sebong Pereh ini memenuhi persyaratan hidup lamun sehingga beberapa jenis lamun dari berukuran kecil hingga berukuran besar dapat hidup dengan baik.

\section{- Kerapatan relatif lamun}

Kerapatan relatif lamun dengan kondisi yang baik memberikan kesempatan dalam pertumbuhan dan kepadatan yang baik. Kepadatan relatif lamun di Desa Sebong Pereh ditampilkan pada Gambar 2. Kerapatan relatif lamun yang didapat dari lapangan pada Stasiun 1 memiliki nilai tertinggi sebesar $29 \%$ pada jenis Cymodocea serrulata dan terendah dengan nilai sebesar 6\% pada jenis Thalassia hemprichii dan Halophila ovalis. Pada Stasiun 2, nilai kerapatan relatif lamun tertinggi sebesar $40 \%$ ditemukan pada jenis Enhalus acoroides dan terendah ditemukan pada jenis Halophila ovalis dengan nilai sebesar $3 \%$. Dua jenis lamun yang tidak ditemukan pada Stasiun 2 tersebut adalah Syringodium isoetifolium dan Cymodocea serrulata. Pada Stasiun 3, kerapatan relatif lamun tertinggi dengan nilai sebesar $72 \%$ ditemukan pada

Tabel 1 Parameter lingkungan

\begin{tabular}{|c|c|c|c|c|}
\hline \multirow{2}{*}{ Parameter } & \multicolumn{3}{|c|}{ Stasiun } & \multirow{2}{*}{ Satuan } \\
\hline & 1 & 2 & 3 & \\
\hline Salinitas & $29,00-30,00$ & $28,00-29,00$ & $29,00-30,00$ & $\%$ \\
\hline Suhu & $27,40-28,80$ & $28,20-29,40$ & $27,00-28,50$ & ${ }^{\circ} \mathrm{C}$ \\
\hline Arus & $0,13-0,15$ & $0,10-0,11$ & $0,11-0,13$ & $\mathrm{~m} /$ det \\
\hline Kekeruhan & $2,25-2,41$ & $2,25-2,30$ & $2,56-2,71$ & NTU \\
\hline TSS & $4,21-4,26$ & $4,63-4,74$ & $4,34-4,47$ & $\mathrm{mg} / \mathrm{L}$ \\
\hline $\mathrm{pH}$ & $7,70-7,90$ & $7,40-7,60$ & $7,20-7,30$ & \\
\hline DO & $6,08-7,20$ & $7,20-7,30$ & $6,90-7,1$ & $\mathrm{mg} / \mathrm{L}$ \\
\hline Nitrat & $0,37-0,38$ & $0,34-0,64$ & $0,32-0,39$ & $\mathrm{mg} / \mathrm{L}$ \\
\hline Fosfat & $0,03-0,04$ & $0,05-0,06$ & $0,02-0,04$ & $\mathrm{mg} / \mathrm{L}$ \\
\hline
\end{tabular}

Tabel 2 Jenis-jenis lamun yang ditemukan pada masing-masing stasiun

\begin{tabular}{llcc}
\multicolumn{1}{c}{ Jenis lamun } & \multicolumn{3}{c}{ Tutupan } \\
\cline { 2 - 4 } & \multicolumn{1}{c}{2} & 3 \\
\hline Enhalus acoraides (Ea) & $\sqrt{ }$ & $\sqrt{ }$ \\
Thalassia hemprichii (Th) & $\sqrt{ }$ & $\sqrt{ }$ \\
Halophila ovalis (Ho) & $\sqrt{ }$ & $\sqrt{ }$ & - \\
Syringodium isoetifolium (Si) & $\sqrt{ }$ & - & - \\
Cymodocea serrulata (Cs) & $\sqrt{ }$ & - & - \\
Thalassodendron ciliatum (Tc) & $\sqrt{ }$ & - \\
\hline
\end{tabular}

Keterangan: $\sqrt{ }$ = Ditemukan dan - = Tidak ditemukan. 
jenis Thalassia hemprichii dan nilai terendah ditemukan pada jenis Enhalus acoroides dengan nilai sebesar $28 \%$. Jenis Halophila ovalis, Syringodium isoetifolium, Cymodocea serrulata, dan Thalassodendron ciliatum tidak ditemukan pada Stasiun 3. Kerapatan jenis lamun dipengaruhi oleh faktor tempat tumbuh lamun tersebut. Lamun jenis Thalassia hemprichii memiliki jumlah yang cukup berlimpah dan sering dominan pada padang lamun campuran pada Stasiun 3. Dua jenis lamun, yaitu Thalassia hemprichii dan Enhalus acoroides, hampir merata pada semua lokasi penelitian di Desa Sebong Pereh, dan hal ini ditambahkan oleh Nontji (2007) yang menyatakan bahwa hampir semua tipe substrat dapat ditumbuhi oleh jenis lamun tersebut.

\section{Indeks Nilai Penting}

Indeks Nilai Penting (INP) memberikan gambaran mengenai peranan suatu jenis tumbuhan pada suatu daerah tertentu. Semakin tinggi nilai INP suatu spesies terhadap spesies lainnya maka semakin tinggi peranan spesies tersebut pada komunitasnya. Nilai INP pada lokasi survei di Desa Sebong Pereh disajikan pada Gambar 3.

Indeks Nilai Penting pada Stasiun 1, yaitu nilai tertinggi sebesar $86 \%$ dijumpai pada lamun jenis
Enhalus acoroides dan nilai terendah sebesar $20 \%$ ditemukan pada lamun jenis Halophila ovalis. Pada Stasiun 2, INP dengan nilai tertinggi sebesar 154\% ditemukan pada lamun jenis Enhalus acoroides dan nilai INP terendah ditemukan pada lamun jenis Halophila ovalis dengan nilai sebesar $10 \%$. Dua jenis lamun yang tidak ditemukan pada Stasiun 2 tersebut adalah Halophila ovalis dan Syringodium isoetifolium. Pada Stasiun 3, nilai INP tertinggi sebesar 167\% ditemukan pada lamun jenis Thalassia hemprichii dan nilai terendah sebesar $133 \%$ ditemukan pada lamun jenis Enhalus acoroides. Lamun jenis Halophila ovalis, Syringodium isoetifolium, Cymodocea serrulata, dan Thalassodendron ciliatum tidak ditemukan pada Stasiun 3. Tuwo (2011) menyebutkan semakin tinggi nilai INP suatu jenis lamun semakin tinggi peranan jenis lamun tersebut pada komunitas tersebut di lokasi penelitiaan.

\section{Sebaran Kelimpahan Kuda Laut dan Kerapatan Ekosistem Lamun}

Kerapatan merupakan struktur komunitas yang dapat digunakan untuk mengestimasi produksi lamun. Hasil pengamatan pada tiap transek menunjukkan kerapatan jenis yang berbeda-beda. Perbedaan kera-

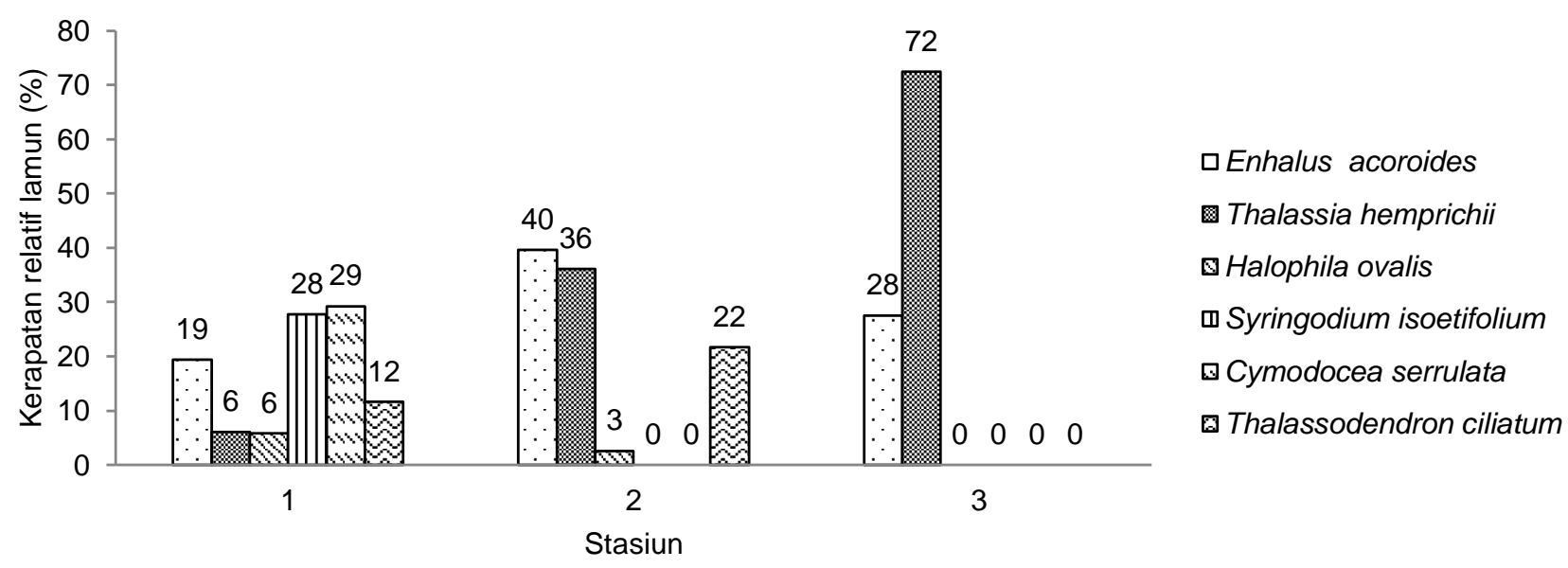

Gambar 2 Kerapatan relatif lamun pada setiap stasiun pengamatan.

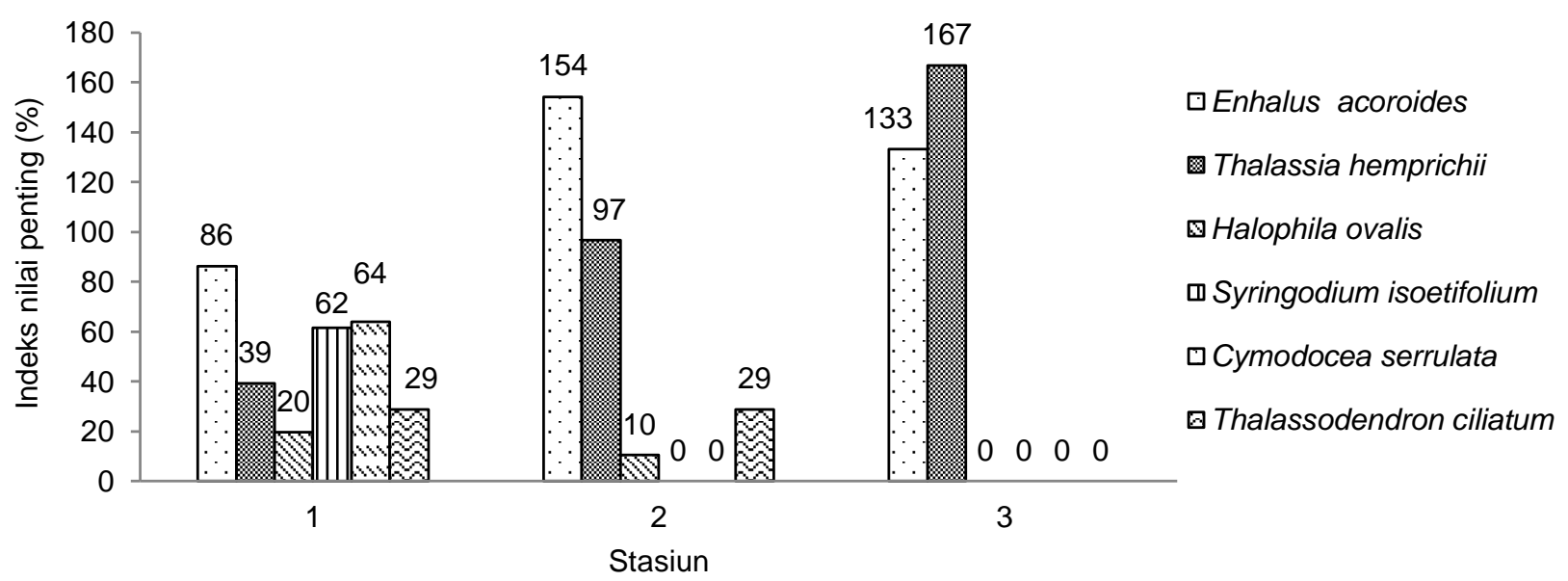

Gambar 3 Indeks nilai penting lamun pada setiap stasiun pengamatan. 
patan pada masing-masing transek menggambarkan bahwa masing-masing lamun memiliki sebaran yang bervariasi. Kerapatan lamun dapat diasumsikan dengan kelimpahan kuda laut yang disurvei pada lokasi. Kerapatan lamun dan kelimpahan kuda laut di Desa Sebong Pereh disajikan pada Gambar 4.

Pada Gambar 4 terlihat dengan jelas sebaran kerapatan ekosistem lamun dan kelimpahan kuda laut. Diketahui bahwa sebaran ekosistem lamun memengaruhi kelimpahan kuda laut. Dengan sebaran lamun yang sedang, kelimpahan kuda laut juga sedang. Sebaran lamun yang jarang memiliki kelimpahan kuda laut yang tinggi karena diketahui bahwa pada ekosistem lamun yang jarang terjadi penangkapan kuda laut yang intensif oleh masyarakat karena kelimpahan kuda laut yang tinggi. Kerapatan ekosistem lamun yang tinggi dipengaruhi oleh ketersediaan substrat tempat tumbuh lamun tersebut (Kiswara 2004).

\section{Hubungan Ekosistem Lamun, Kuda Laut, dan Parameter Lingkungan}

Pada Gambar 5 terlihat hubungan antara ekosistem lamun, kuda laut, dan parameter lingkungan. Garisgaris yang berdekatan menandakan bahwa faktorfaktor tersebut saling berhubungan. Dari gambaran tersebut diketahui bahwa $\mathrm{Cs}$, Si, nitrat, Ho, Tc, kuda laut, dan DO (oksigen terlarut) pada Stasiun 1 saling berhubungan, sementara pada Stasiun 2, suhu, fosfat, Ea, dan TSS saling berhubungan. Masing-masing paremeter memberikan hubungan yang erat bagi kehidupan lamun, kualitas perairan, dan kuda laut.

Hubungan Halophila ovalis (Ho) dan nitrat kelihatannya erat yang ditunjukkan oleh pertumbuhan jenis Halophila ovalis yang sangat dipengaruhi oleh nitrat. Hal ini sesuai dengan pernyataan Raymont (1961) bahwa kosentrasi nitrat kurang dari $0,9 \mathrm{mg} / \mathrm{l}$ mempunyai pengaruh yang kurang pada pertumbuhan organisme, konsentrasi nitrat sekitar 0,9-3,5 mg/l mempunyai pengaruh yang optimum pada partum-

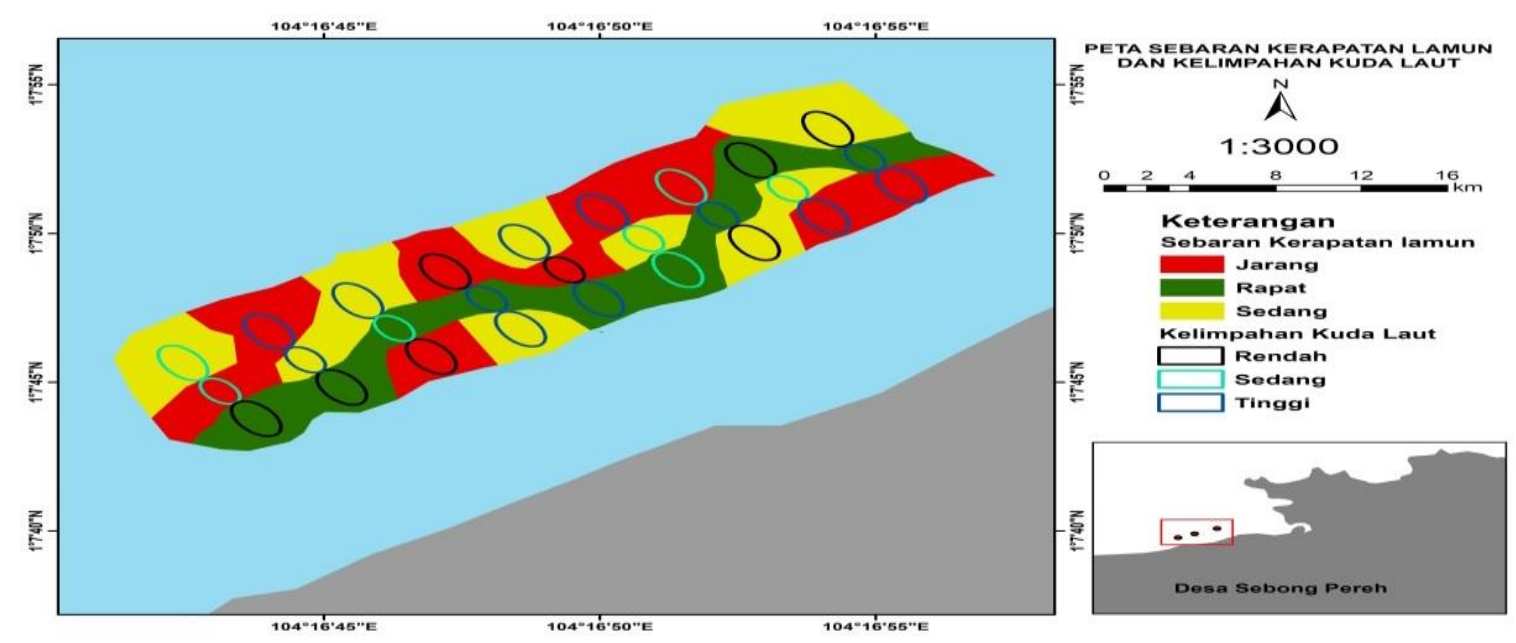

Gambar 4 Sebaran kerapatan lamun dan kelimpahan kuda laut pada setiap stasiun pengamatan.

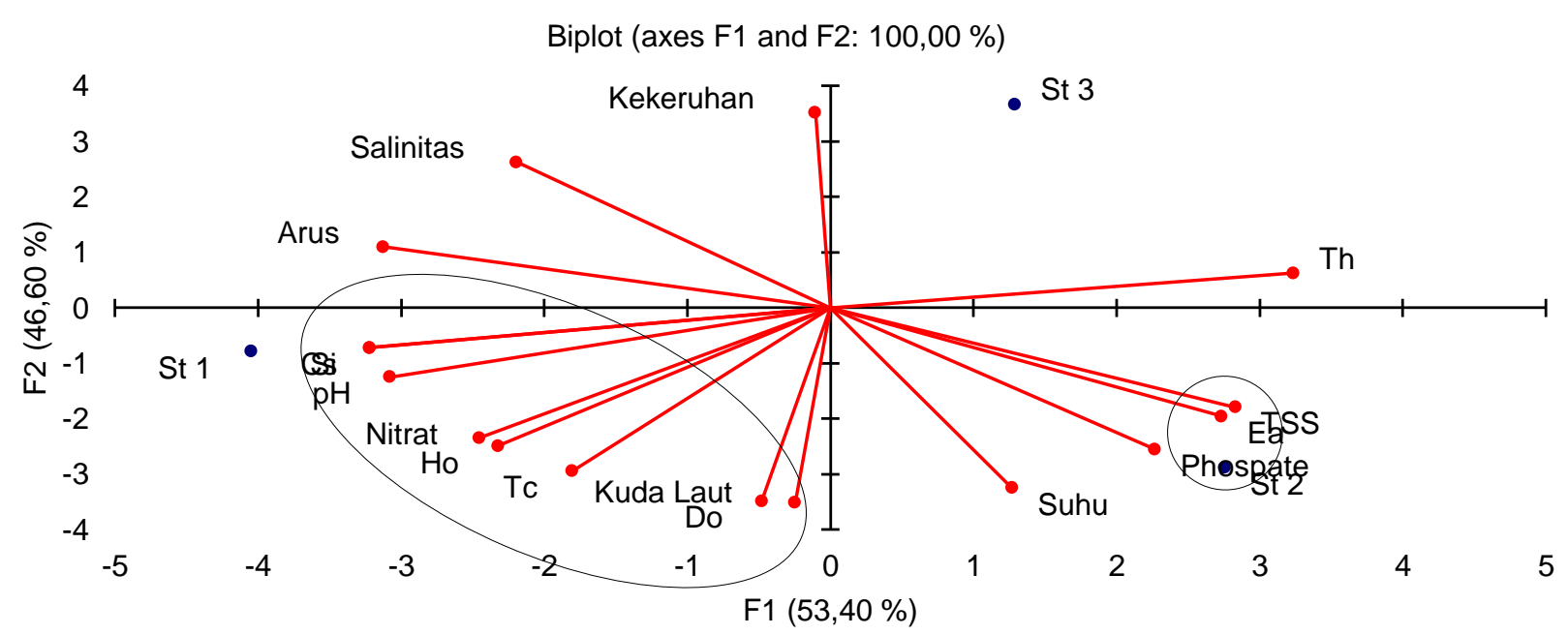

Gambar 5 Hubungan ekosistem lamun, kuda laut, dan parameter lingkungan. Ea = Enhalus acoroides, Th =Thalassia hemprichii, $\mathrm{Ho}=$ Halophila ovalis, $\mathrm{Si}=$ Syringodium isoetifolium, $\mathrm{Cs}=$ Cymodocea serrulata, dan $\mathrm{Tc}=$ Thalassodendron ciliatum. 
buhan organisme, dan pada konsentrasi nitrat $>3.5$ $\mathrm{mg} / \mathrm{l}$ menjadi membahayakan perairan. Nitrat pada lokasi penelitian ini masuk ke dalam golongan rendah di mana nilai nitrat didapati pada kisaran $0,34-0,38$ yang menjadi kadar nitrat yang baik untuk pertumbuhan jenis Halophila ovalis (Ho).

Hubungan antara oksigen terlarut atau DO dan kuda laut ialah kuda laut sangat membutuhkan DO untuk siklus hidupnya. Nilai DO yang didapati dari hasil lapangan adalah $7 \mathrm{mg} / \mathrm{l}$ yang berada pada kisaran DO yang baik untuk kehidupan biota laut yang menurut Keputusan Menteri LH No. 200 (2004) adalah > 5 mg/l.

Nilai TSS yang didapat dari lapangan adalah sebesar 4,4 mg/L. Menurut Alabaster \& Lloyd (1982), nilai TSS $<25 \mathrm{mg} / \mathrm{l}$ tidak berpengaruh pada penangkapan kuda laut. TSS yang tinggi dapat memengaruhi cahaya matahari sehingga mengganggu fotosintesis yang dapat menghambat pertumbuhan Enhalus acoroides.

\section{Strategi Pengelolaan Ekosistem Lamun Berbasis Kuda Laut}

Pengelolaan ekosistem lamun berbasis kuda laut di Desa Sebong Pereh memiliki empat strategi yang dihasilkan menjadi awal pengelolaan suatu kawasan yang akan dijalankan dengan program-program penunjang. Ranking Alternatif strategi ditampilkan pada Tabel 3.

Strategi yang dihasilkan menjadi awal pengelolaan suatu kawasan yang akan direalisasikan dengan program-program penunjang. Berdasarkan jumlah skor setiap alternatif strategi maka urutan yang dapat dijadikan rencana strategi dalam pengelolaan ekosistem lamun di perairan Desa Sebong Pereh ialah:

- Sosialisasi kepada masyarakat tentang fungsi ekosistem lamun agar hasil tangkapan tidak berkurang pada saat musim kuda laut di Desa Sebong Pereh.

- Ketersedian ekosistem lamun yang baik membuat masyarakat memanfaatkan untuk menangkap kuda laut pada musimnya.

Tabel 3 Rangking strategi alternatif
- Meningkatkan pengetahuan masyarakat melalui pembinaan dan penyuluhan kepada semua lapisan akan arti pentingnya ekosistem lamun untuk keberadaan kuda laut serta menjaga kelestariannya.

- Penetapan daerah penangkapan kuda laut di ekosistem lamun agar pembuangan limbah tidak masuk ke kawasan penangkapan.

Pengelolaan ekosistem lamun di Desa Sebong Pereh dan di daerah Kampung Holtekamp memiliki kesamaan. Dalam rangka pengelolaan yang baik, perlu dilakukan sosialisasi kepada masyarakat tentang fungsi-fungsi ekosistem lamun, pelaksanaan kegiatan aksi bersih lingkungan untuk menjaga mutu dan kualitas lingkungan, mengintensifkan kegiatan pengawasan atas ekosistem lamun dan daerah sekitarnya, dan menetapkan peraturan kampung tentang pelestarian sumber daya ekosistem lamun dan konservasi ekosistem padang lamun (Metekohy 2016). Pengelolan yang terjadi pada setiap daerah tidak terlepas dari masyarakat setempat yang memanfaatkan ekosistem lamun. Dengan demikian, instansi terkait diharapkan perlu memberikan sosialisasi dan pendampingan untuk dapat memberikan rasa aman bagi masyarakat terkait sehingga dilakukan pemanfaatan yang berkelanjutan.

\section{KESIMPULAN}

Jenis lamun di perairan Desa Sebong Pereh terdiri atas Enhalus acoraides, Thalassia hemprichii, Halophila ovalis, Syringodium isoetifolium, Cymodocea serrulata, dan Thalassodendron ciliatum. Sebaran ekosistem lamun memengaruhi kelimpahan kuda laut. Strategi pengelolaan kegiatan ekosistem lamun di pesisir Desa Sebong Pereh adalah dengan meningkatkan kegiatan sosialisasi ke masyarakat tentang fungsi ekosistem lamun untuk kelestarian biota yang berasosiasi, mengontrol pemanfaatan lamun berbasis masyarakat, dan juga memberikan sangsi atas pelanggaran-pelanggaran yang merusak ekosistem lamun.

\begin{tabular}{|c|c|c|c|}
\hline Unsur SWOT & Keterkaitan & Jumlah bobot & Rangking \\
\hline \multicolumn{4}{|l|}{ Strategi SO } \\
\hline $\begin{array}{l}\text { Ketersedian ekosistem lamun yang baik membuat } \\
\text { masyarakat memanfaatkan untuk menangkap kuda laut } \\
\text { pada musimnya }\end{array}$ & $\begin{array}{l}\mathrm{S} 1, \mathrm{~S} 2, \mathrm{~S} 7, \mathrm{~S} 8, \mathrm{~S} 9 \\
\mathrm{~S} 10, \mathrm{~S} 10, \mathrm{O} 1, \mathrm{O} 2 \\
\mathrm{O} 7\end{array}$ & 3,311 & 2 \\
\hline \multicolumn{4}{|l|}{ Strategi WO } \\
\hline $\begin{array}{l}\text { Sosialisasi kepada masyarakat tentang fungsi ekosistem } \\
\text { lamun agar hasil tangkapan tidak berkurang pada saat } \\
\text { musim kuda laut }\end{array}$ & $\begin{array}{l}\text { W1, W2, W3, W4, } \\
\text { W6, W9, O4, O5, } \\
\text { O8, O10 }\end{array}$ & 3,363 & 1 \\
\hline \multicolumn{4}{|l|}{ Strategi ST } \\
\hline $\begin{array}{l}\text { Penetapan daerah penangkapan kuda laut di ekosistem } \\
\text { lamun agar pembuangan limbah tidak masuk ke } \\
\text { kawasan penangkapan }\end{array}$ & $\begin{array}{l}\text { S1, S3, S6, S8, T1, } \\
\text { T5, T7, T8 }\end{array}$ & 3,078 & 4 \\
\hline \multicolumn{4}{|l|}{ Strategi WT } \\
\hline $\begin{array}{l}\text { Meningkatkan pengetahuan masyarakat melalui } \\
\text { pembinaan dan penyuluhan kepada semua lapisan akan } \\
\text { arti pentingnya ekosistem lamun untuk keberadaan kuda } \\
\text { laut serta menjaga kelestariannya }\end{array}$ & $\begin{array}{l}\text { W2, W3, W4, W6, } \\
\text { W9, T1, T3, T7, T8 }\end{array}$ & 3,13 & 3 \\
\hline
\end{tabular}




\section{DAFTAR PUSTAKA}

Alabaster JS, R Lloyd. 1982. Water Quality Criteria for Freshwater Fish. London, Boston (ID): Food and Agricultural Organization of the United Nation.

Calef Z, Ferber P, Fedrizzi N. 2011. Summary Of Seahorse Population and Distribution Koh Rong Samloem Preah Sihanouk, Cambodia. Marine Conservation Cambodia.

Harahap N, Raymon G. 2011. Analisis indikator utama pengelolaan hutan mangrove berbasis masyarakat di Desa Curahsawo Kecamatan Gending Kabupaten Probolinggo. Jurnal Sosek Kelautan Perikanan. 6 (1): 29-37.

Hemminga M, CM Duarte. 2000. Seagrass Ecology. Cambridge (EN): Cambridge University Press.

Juraij. 2016. Hubungan Fungsional Sebaran Jenis Lamun Dengan Kemunculan Dugong-dugong di Pulau Bintan (Desa Pengudang \& Desa Busung) Kepulauan Riau. [tesis]. Bogor ID: Institut Pertanian Bogor.

Kawaroe M. 2009. Perspektif Lamun Sebagai Blue Carbon Sink di Laut. Lokakarya Lamun. Bogor (ID): Departemen IImu dan Teknologi Kelautan Fakultas Perikanan dan IImu Kelautan. IPB.

Kiswara W. 2004. Kondisi Padang Lamun (seagrass) di Teluk Banten 1998-2001. Jakarta (ID): Pusat Penelitian dan Pengembangan Oseanologi Lembaga Ilmu Pengetahuan Indonesia.

[MENLH] Keputusan Menteri Negara Lingkungan Hidup. Kriteria Baku. 2004. Kerusakan dan Pedoman Penentuan Status Padang Lamun. Keputusan Menteri Negara Lingkungan Hidup Nomor 200 tahun 2004.

Metekohy AE. 2016. Strategi Pengelolaan Ekosistem Lamun di Perairan Pantai Kampung Holtrkamp Distrik Muara Tami Kota Jayapura Provinsi Papua. The Journal of Fisheries Development. 3(1): 1-10.

Nontji A. 2007. Laut Nusantara. Jakarta (ID): Djambatan.

Nybakken JW. 1992. Biologi Laut Suatu Pendekatan Ekologis. Jakarta (ID): PT. Gramedia.
Perante NC, Vincent ACJ, Pajaro MG. 1998. Demographics of The Seahorse Hippocampus Comes in The Central Philippines. $3^{\text {rd }}$ International Conference on The Marine Biology of The South China Sea. HongKong (HK): 439-448.

Rahmawati S, Irawan A, Supriyadi IH, Husni M. 2014. Panduan Monitoring Padang Lamun. Hutomo M, Nontji A (Editor). Bogor (ID): PT Sarana Komunikasi Utama.

Rangkuti F. 2011. SWOT Balanced Scorecard Teknik Penyusunan Strategi Korporat yang Efektif Plus cara Mengelola Kinerja dan Resiko. Jakarta (ID): PT. Gramedia.

Raymont JEG. 1961. Plankton and Produktivity In The Ocea, 2nd Edition, Vol 1 phyro, Oxford (ID): Pergamon Press.

Romimohtarto K, Juwana S. 2001. Biologi Laut. IImu Pengetahuan Tentang Biota Laut. Jakarta (ID): Djambatan.

Sadili S, Sarmintohadi, Ramli I, Rasdiana H, Sari PR, Miasto Y, Prabowo, Monintja M, Terry N, Annisa S. 2015. Pedoman Pengkayaan Populasi Kuda Laut (Hippocampus Spp). Jakarta (ID): Kementerian Kelautan dan Perikanan. $68 \mathrm{hlm}$.

Sugiyono. 2015. Metode Penelitian Kombinasi (Mix Methods). Bandung (ID): Alfabeta.

Tuwo A. 2011. Pengelolaan Ekowisata Pesisir dan Laut. Pendekatan Ekologi, Sosial-Ekonomi, Kelembagaan, dan Sarana Wilayah. Surabaya (ID): Brilian Internasional.

Utomo PBN, Sulistiono, Affandi R, Nugroho T, Murhum M, Manan H. 2018. Penampungan Lobster (Panulirus spp) dalam Rangka Pemberdayaan Masyarakat di Pulau Gebe, Halmahera Tengah, Maluku Utara (Stocking of Lobster (Panulirus spp). Agrokreatif Jurnal Ilmiah Pengabdian kepada Masyarakat. 4(2): 81-91.

Vincent ACJ. 1996. The International Trade in Seahorses. Cambridge (EN): TRAFFIC International. 